\section{Saúde bucal de idosos residentes em instituições de longa permanência de Belo Horizonte, Minas Gerais, Brasil}

\author{
Oral health among institutionalized elderly in \\ Belo Horizonte, Minas Gerais State, Brazil
}

1 Centro de Ciências Biológicas e da Saúde, Universidade Estadual de Montes Claros, Montes Claros, Brasil.

2 Faculdades Unidas do Norte de Minas, Montes Claros, Brasil.

3 Faculdade de Odontologia Universidade Federal de Minas Gerais, Belo Horizonte, Brasil.

Correspondência R. C. Ferreira Departamento de Odontologia, Centro de Ciências Biológicas e da Saúde, Universidade Estadual de Montes Claros. Av. Ouro Preto 378 , Perdigão, $M G$

35515-000, Brasil. ferreira_rc@hotmail.com

\section{Abstract}

This study assessed the oral health of the institutionalized elderly in Belo Horizonte, Minas Gerais State, Brazil. A sample of 335 individuals over 60 years of age was randomly selected. Data were collected through interviews, review of medical records, and clinical examination by a single researcher. Oral health was evaluated in terms of oral hygiene, caries, and periodontal disease. Bacterial plaque was present on $76 \%$ of the dental surfaces, and $57 \%$ of the elderly using upper dentures presented plaque on at least one of its surfaces. DMF-T index was 30.8, with the missing component representing 94.2\%. Missing sextant was the worst periodontal finding in $78.2 \%$ of the elderly. Among the valid sextants, there was a higher prevalence of 4 to $5 \mathrm{~mm}$ periodontal pocket and attachment loss from 4 to $5 \mathrm{~mm}$ (47\%). According to the findings, institutionalized elderly suffer from precarious oral health, with deficient oral hygiene, high caries rate, tooth loss, and periodontal pocket.

Homes for the Aged; Oral Health; Health of the Elderly
Raquel Conceição Ferreira 1,2 Cláudia Silami de Magalhães 3 Enia Salles Rocha ${ }^{3}$ Carolina Wolff Schwambach ${ }^{3}$ Allyson Nogueira Moreira 3

\section{Introdução}

A transição demográfica produz como cenário uma população com elevado número de indivíduos idosos. Juntamente com o envelhecimento populacional, a transição epidemiológica resulta no aumento da demanda por serviços de saúde. A saúde bucal merece atenção dentre os vários aspectos da saúde do idoso, pois historicamente os serviços odontológicos não possuíam como prioridade a atenção a esse grupo etário 1 .

No levantamento epidemiológico em saúde bucal realizado no Brasil pelo Ministério da Saúde 2 , a perda dentária foi considerada um grave problema no grupo etário de 65 a 74 anos. Outros estudos no Brasil, desde o início da década de 1990, até recentemente mostraram altas taxas de edentulismo, elevada experiência de cárie dentária e presença de doença periodontal nos poucos dentes remanescentes $1,3,4,5,6,7,8,9,10$. Esses estudos envolveram idosos domiciliares, institucionalizados, pacientes de centros de saúde, participantes de grêmios ou programas para idosos. Idosos institucionalizados apresentaram maior prevalência de cárie coronária e pior condição periodontal que os não-institucionalizados, em Araraquara, São Paulo, Brasil 5. Apesar da afirmação de que idosos institucionalizados apresentaram maior chance de edentulismo, não foi demonstrado o efeito da institucionalização na deterioração da saúde bucal 11 . 
Embora os vários estudos concordem com a precariedade da saúde bucal dos idosos brasileiros, os dados disponíveis não são suficientes para uma análise mais detalhada em relação àqueles institucionalizados, pois são, na sua maioria, provenientes de amostras não probabilísticas, selecionadas por conveniência ou envolvendo uma única ou um pequeno número de instituições, ou instituições de uma única região do município. Em estudos anteriores, a condição de saúde bucal dos idosos institucionalizados foi caracterizada quanto à prevalência de cárie coronária, doença periodontal, uso e necessidade de próteses. A condição radicular foi descrita em um estudo com idosos de uma única instituição de Piracicaba, São Paulo 6 e uma de Fortaleza, Ceará 7 .

A pobre higiene bucal entre idosos institucionalizados pode aumentar o risco de desenvolvimento de cárie, especialmente radicular, periodontites, candidíase e estomatite por dentadura e relato de queixas, tais como halitose 12,13. Além disso, os dentes e as próteses dentárias podem ser reservatórios de patógenos respiratórios e a sua aspiração tem sido apontada como uma causa de pneumonia entre idosos 14. No Brasil, não foram encontrados trabalhos avaliando a higiene bucal de idosos.

Com vistas à elaboração de estratégias que promovam saúde de idosos institucionalizados, torna-se necessário conhecer a real situação de saúde bucal nesse grupo populacional. Diante do exposto, o objetivo desse estudo foi descrever a saúde bucal dos idosos residentes em instituições de longa permanência de Belo Horizonte, Minas Gerais, Brasil, quanto à higiene bucal, cárie dentária coronária e radicular e doença periodontal.

\section{Metodologia}

Trata-se de um estudo transversal, cuja coleta de dados foi realizada entre novembro de 2005 e junho de 2006.

\section{População estudada}

O universo foi formado por 1.669 indivíduos com mais de 60 anos de idade residentes em 65 instituições de longa permanência, sendo 32 filantrópicas e 33 privadas, distribuídas nas nove regionais administrativas de Belo Horizonte. A amostra foi calculada por meio da fórmula de estimativa para proporções considerando uma prevalência de $50 \%$, erro amostral de 0,05 , nível de $95 \%$ de confiança e significância de $5 \%$. Após correção para população finita, uma amostra final de 313 idosos foi obtida. Visando resguardar a precisão, optou-se por majorar a amostra em $10 \%$ a fim de compensar eventuais perdas, obtendo-se número final de 345 idosos.

A seleção da amostra foi realizada por meio de amostragem aleatória, estratificada e proporcional considerando os seguintes estratos, nesta ordem: modalidades das instituições (filantrópica e privada), localização das instituições nas regionais administrativas da cidade (leste, oeste, norte, centro-sul, nordeste, noroeste, Venda Nova, Barreiro e Pampulha) e gênero dos residentes. A proporcionalidade do tamanho de cada estrato da população foi mantida na amostra. Em cada instituição, os idosos, de ambos os sexos, foram aleatoriamente selecionados empregando uma tabela de números aleatórios.

Os idosos doentes terminais e aqueles que, devido à grande agressividade ou alterações de comportamento não permitiram o exame clínico ou não contribuíram para a entrevista foram excluídos do estudo. Os idosos com perda cognitiva, avaliada pelo Mini-Exame do Estado Mental, foram excluídos do estudo desde que as informações sócio-demográficas não estivessem registradas nos documentos da instituição. Foi empregada a versão testada e validada no Brasil do Mini-Exame do Estado Mental 15,16, considerando como ponto de corte os escores medianos obtidos por Brucki et al. 15 segundo a escolaridade - analfabetos: 20; 1-4 anos de estudo: 25; 5-8 anos de estudo: 26,5; 9-11 anos de estudo: 28; $>12$ anos de estudo: 29 .

Os idosos e os coordenadores das instituições assinaram o termo de consentimento anteriormente ao início do estudo, que foi aprovado pelo Comitê de Ética em Pesquisa da Universidade Federal de Minas Gerais (ETIC/UFMG 004/05).

\section{Coleta de dados}

Os dados foram coletados por meio de pesquisa nos registros da instituição, entrevista com os idosos e exame clínico da cavidade bucal.

\section{Características sócio-demográficas e comportamentais}

Os idosos foram caracterizados quanto à idade, gênero, escolaridade (anos de estudo), estado civil, tempo de institucionalização e renda, estimada pelo valor de contribuição paga à instituição. Esse método foi escolhido pelo fato dos idosos não terem acesso a seus salários, o que os impossibilitou de responder sobre sua renda individual. 


\section{Higiene bucal}

A higiene bucal nos idosos dentados foi avaliada por meio do índice de Silness \& Löe 17 modificado por Ainamo \& Bay 18 , onde escores 0 ou 1 foram atribuídos às superfícies vestibular e lingual de todos os dentes segundo a presença ou ausência de placa bacteriana visível (índice de placa visível - IPV). Nos idosos edêntulos, usuários de prótese total superior, foi empregado o índice de limpeza da prótese proposto por Ambjorsen et al. 19. A presença ou ausência de placa bacteriana foi registrada em cinco áreas da superfície interna da prótese total superior após uma rápida lavagem com água.

\section{Cárie dentária}

O exame clínico para avaliação de cárie dentária coronária e radicular foi realizado adotando os códigos e critérios de diagnóstico preconizados pela Organização Mundial da Saúde (OMS) 20. A experiência de cárie dentária foi avaliada pelo índice de dentes cariados, perdidos e restaurados - CPOD. No cálculo, todos os dentes perdidos foram computados no índice de cárie devido à dificuldade para obtenção de resposta quanto à causa da perda dentária. O COR, que é o resultado da soma de raízes cariadas e obturadas, foi calculado para avaliação da experiência de cárie radicular 20 . Não foram realizadas radiografias.

\section{Doença periodontal}

O índice periodontal comunitário (CPI) e o índice de perda de inserção periodontal (PIP) foram empregados para avaliação da condição periodontal. A cavidade bucal foi dividida em sextantes, que receberam escores segundo a pior condição observada, para cada um dos índices: 0 - sextante hígido e perda de inserção entre 0 e 3mm; 1 - sextante com presença de sangramento em pelo menos um dos dentes e perda de inserção de 4 a 5mm; 2 - presença de cálculo supra ou subgengival e perda de inserção de 6 a $8 \mathrm{~mm} ; 3$ - bolsa periodontal de 4 a $5 \mathrm{~mm}$ e perda de inserção de 9 a 11mm; 4 - bolsa periodontal com $6 \mathrm{~mm}$ ou mais e perda de inserção de $\geq 12 \mathrm{~mm}$. Foram considerados os dentes índices preconizados pela OMS $(17,16,11,26,27,47,46$, 31,36 e 37) 20. Na ausência dos dentes índices em um sextante qualificado para o exame, todos os dentes remanescentes naquele sextante foram examinados e o índice mais alto registrado. No presente estudo, a raspagem supragengival foi realizada previamente à sondagem periodontal quando da presença de cálculo inviabilizando tal procedimento.
Os exames clínicos foram realizados empregando espelho bucal e sonda periodontal modelo da Universidade da Carolina do Norte (HuFriedy, Chicago, Estados Unidos), na própria instituição, com os idosos sentados em cadeiras odontológicas portáteis, em cadeiras de roda ou em seus leitos, sob iluminação de um refletor portátil. A entrevista com o idoso e o exame clínico da cavidade bucal foram realizados por um único pesquisador.

Os dados foram submetidos à análise descritiva. A comparação do CPOD, do CPI e do PIP segundo gênero e faixa etária foi realizada pelos testes Kruskall-Wallis e Mann-Whitney, tendo em vista a ausência de distribuição normal dos dados, verificada pelo teste Kolmogorov-Smirnov. Para análise dos dados, empregou-se o pacote estatístico SPSS versão 12 (SPSS Inc., Chicago, Estados Unidos).

\section{Treinamento do examinador}

O examinador participou de um treinamento teórico e clínico previamente ao estudo principal para calibração intra-examinador. Exames repetidos para a coleta do IPV e do índice de limpeza de prótese foram realizados com intervalo de uma hora e de uma semana para cárie dentária, presença de cálculo e profundidade à sondagem. As concordâncias das medidas categóricas (IPV, índice de limpeza de prótese, presença de cálculo, CPOD e COR) foram verificadas pelo teste kappa. A concordância das medidas de profundidade à sondagem (PS) e perda de inserção (PI) foi avaliada pelo cálculo do coeficiente de correlação intraclasse. Os resultados obtidos para cada uma das condições foram: IPV $(0,98)$, índice de limpeza de prótese total $(0,88)$, presença de cálculo $(0,95)$, CPOD $(0,89)$, COR $(0,92)$, PS vestibular $(0,89)$, PS lingual $(0,82)$, PS distal $(0,85)$, PS mesial $(0,89)$ e PI vestibular $(0,85)$, PI lingual $(0,87)$, PI distal $(0,92)$, PI mesial $(0,90)$.

\section{Exames em duplicata}

Foram realizados em 20 idosos dentados (25\%) para verificar o erro intra-examinador na avaliação de cárie dentária, presença de cálculo e de doença periodontal ao longo da coleta de dados. Empregando os mesmos cálculos anteriormente descritos na fase de treinamento, os valores de concordância obtidos para cada condição foram: $\mathrm{CPOD}=0,96 ; \mathrm{COR}=0,98$; presença de cálculo = 0,95 ; PS vestibular $=1,0 ;$ PS lingual $=0,98 ;$ PS mesial $=1,0 ;$ PS distal $=0,97$; PI vestibular $=0,97 ; \mathrm{PI}$ lingual =0,98; PI mesial = 1,0; PI distal $=0,99$. 


\section{Resultados}

Uma amostra de 335 idosos participou do estudo, sendo 225 em 10 instituições filantrópicas e 110 em 13 privadas. As razões para a perda de dez indivíduos foram: recusa do exame por ser o dentista um desconhecido do paciente $(n=3)$, idosos que consideraram o estudo sem importância $(n=2)$, aqueles que se sentiram incomodados com a pesquisa $(\mathrm{n}=2)$, ou ainda, os que não estavam se sentindo bem no momento da coleta de dados $(n=3)$.

A média de idade foi de 79 anos $( \pm 9,1 ; 60$ a 105), sendo maior entre as mulheres (mulheres: $80,3 \pm 8,9$; homens: $75,5 \pm 8,7$ ). Os idosos eram, na sua maioria, mulheres, viúvos ou solteiros e metade deles possuía mais de 80 anos. Os indivíduos estudados apresentaram, em geral, baixo nível de escolaridade e eram institucionalizados há menos de cinco anos. A maior parte dos idosos pagava à instituição menos de um salário mínimo por mês (Tabela 1).

\section{Higiene bucal}

A higiene bucal nos indivíduos dentados $(\mathrm{n}=84)$ foi precária, com presença de placa bacteriana em $76 \%$ das superfícies avaliadas $(n=1.824$ superfícies). Somente um idoso $(1,2 \%)$ não possuía placa bacteriana, $24,1 \%$ e $25,3 \%$ apresentaram placa em $12 \%$ a $65 \%$ e $67 \%$ a $96 \%$ das superfícies dentárias, respectivamente, e 49,4\% possuíam placa em todas as superfícies avaliadas. Entre os usuários de prótese total superior $(n=157), 57 \%$ possuíam placa em pelo menos uma das superfícies da mesma, distribuídos como segue: placa em cinco superfícies da prótese (34\%), quatro (3\%), três (7\%), duas (7\%) e uma (6\%).

\section{Cárie dentária coronária e radicular}

O índice CPOD foi de 30,8 dentes $( \pm 3,2)$, com o componente perdido representando $94,2 \%$. Houve um aumento significativo do índice com o aumento da faixa etária de 60 a 69 anos para 80 anos ou mais; resultado do aumento significativo do componente "perdido" e redução significativa dos componentes "cariado" e "restaurado" (Tabela 2). O edentulismo foi observado em 251 idosos $(74,9 \%)$ e $59(17,6 \%)$ apresentaram pelo menos um dente cariado na cavidade bucal.

A condição da coroa foi avaliada considerando os dentes remanescentes (mil dentes) entre os 84 idosos dentados, sendo observado: dentes hígidos $(38,6 \%)$, cariados ou restaurados com cárie $(19,8 \%)$, restauração sem cárie $(38,6 \%)$ e suporte para prótese fixa (3\%). O número médio de dentes remanescentes por indivíduo
Tabela 1

Distribuição dos idosos residentes em instituições de longa permanência, segundo gênero, faixa etária, estado civil, anos de estudo, tempo de institucionalização e renda. Belo Horizonte, Minas Gerais, Brasil, 2006

\begin{tabular}{|c|c|c|}
\hline Variáveis & $\mathrm{n}$ & $\%$ \\
\hline \multicolumn{3}{|l|}{ Gênero } \\
\hline Feminino & 245 & 73,1 \\
\hline Masculino & 90 & 26,9 \\
\hline \multicolumn{3}{|c|}{ Faixa etária (anos) * } \\
\hline $60-69$ & 53 & 15,9 \\
\hline $70-79$ & 114 & 34,1 \\
\hline 80 ou mais & 167 & 50,0 \\
\hline \multicolumn{3}{|l|}{ Estado civil } \\
\hline Solteiro & 137 & 40,9 \\
\hline Casado & 20 & 6,0 \\
\hline Viúvo & 144 & 43,0 \\
\hline Divorciado & 34 & 10,1 \\
\hline \multicolumn{3}{|l|}{ Anos de estudo } \\
\hline 0 & 91 & 27,2 \\
\hline $1-4$ & 146 & 43,6 \\
\hline $5-8$ & 39 & 11,6 \\
\hline $9-12$ & 46 & 13,7 \\
\hline 12 ou mais & 13 & 3,9 \\
\hline \multicolumn{3}{|c|}{ Tempo de institucionalização (anos) ** } \\
\hline $1-5$ & 230 & 70,3 \\
\hline 6 ou mais & 97 & 29,7 \\
\hline \multicolumn{3}{|c|}{ Renda (salários mínimos) } \\
\hline Até 1 & 214 & 63,9 \\
\hline$\geq 1$ & 121 & 36,1 \\
\hline Total & 334 & - \\
\hline
\end{tabular}

* Ausência de registro de data de nascimento de um idoso; ** Oito instituições sem data de entrada do idoso.

foi 3, sendo que, em média, 1,1 encontravam-se hígidos.

Os 84 idosos dentados apresentaram 584 raízes expostas $(58,4 \%)$, sendo a maioria hígida (76\%); 14,4\% estavam cariadas e $9,6 \%$ obturadas. Experiência atual ou passada de cárie radicular foi observada em $57,1 \%$ dos idosos, que apresentaram COR $\geq 1$ (COR $1=21,4 \%$; COR $2=8,3 \%$, COR $3=10,7 \%$, COR $\geq 4=16,7 \%$ ). Foi observado COR $=0$ em 36 idosos $(42,9 \%)$.

\section{Condição periodontal}

Não foi possível realizar a avaliação periodontal em três indivíduos, dois por apresentarem um quadro de diabetes mellitus descompensada, que contra-indicou a sondagem periodontal e 
Média do CPOD e seus componentes na população total e diferenças segundo gênero e faixa etária. Belo Horizonte, Minas Gerais, Brasil, 2006.

\begin{tabular}{|c|c|c|c|c|c|c|c|c|}
\hline \multirow[t]{3}{*}{ Variávies } & \multirow[t]{3}{*}{$\mathrm{n}$} & \multirow{3}{*}{$\begin{array}{l}\text { Média do } \\
\text { CPOD (DP) }\end{array}$} & \multicolumn{6}{|c|}{ Componentes do CPOD } \\
\hline & & & \multicolumn{2}{|c|}{ Cariado } & \multicolumn{2}{|c|}{ Perdido } & \multicolumn{2}{|c|}{ Restaurado } \\
\hline & & & Média (DP) & $\%$ & Média (DP) & $\%$ & Média (DP) & $\%$ \\
\hline CPOD & 335 & $30,8(3,2)$ & $0,6(1,9)$ & 1,9 & $29,0(6,2)$ & 94,2 & $1,2(3,3)$ & 3,9 \\
\hline \multicolumn{9}{|l|}{ Gênero } \\
\hline Masculino & 90 & 30,5 a $(3,7)$ & $0,5 a(1,5)$ & 1,7 & $28,8 \mathrm{a}(6,6)$ & 94,4 & $1,2 \mathrm{a}(3,6)$ & 3,4 \\
\hline Feminino & 245 & $30,8 \mathrm{a}(3,0)$ & $0,6 \mathrm{a}(2,0)$ & 2,0 & $29,1 \mathrm{a}(6,1)$ & 94,3 & $1,2 a(3,1)$ & 3,7 \\
\hline \multicolumn{9}{|c|}{ Faixa etária (anos) * } \\
\hline $60-69$ & 53 & 29,6 a $(4,6)$ & 1,1 a $(3,0)$ & 3,7 & 26,5 a $(8,3)$ & 89,6 & $2,0 \mathrm{a}(4,5)$ & 6,7 \\
\hline $70-79$ & 114 & $30,8 \mathrm{ab}(3,2)$ & $0,8 \mathrm{ab}(1,9)$ & 2,6 & $28,9 \mathrm{ab}(6,0)$ & 93,8 & $1,1 \mathrm{ab}(2,9)$ & 3,6 \\
\hline 80 ou mais & 167 & $31,1 \mathrm{~b}(2,6)$ & $0,4 b(1,2)$ & 1,0 & $29,9 \mathrm{~b}(5,4)$ & 95,8 & $0,9 b(3,0)$ & 2,9 \\
\hline
\end{tabular}

DP: desvio-padrão.

Nota: a comparação foi realizada empregando teste Kruskall-Wallis e teste Mann Whitney com correção de Bonferrone para a comparação em pares. As letras diferentes comparadas verticalmente significam diferença estatística significativa ( $p<0,02$ para faixa etária nas comparações em pares).

* Um idoso com data de nascimento desconhecida.

um por não permitir a realização do exame. Assim, para obtenção do CPI e do PIP, foram avaliados 332 indivíduos, sendo que somente 73 (22\%) possuíam pelo menos um sextante válido. A pior condição periodontal foi sextante nulo para $78 \%$ dos idosos, seguida por bolsas periodontais de 4 a $5 \mathrm{~mm}$, presente em $14,8 \%$ dos examinados e em $64,5 \%$ dos sextantes válidos. Quanto ao PIP, desconsiderando sextantes nulos, predominou a perda de inserção de 6 a $8 \mathrm{~mm}$ como pior condição, presente em 9,3\% dos idosos. No entanto, entre os sextantes, houve predomínio de perda de inserção de 4 a $5 \mathrm{~mm}$, diagnosticada em $47 \%$ dos sextante válidos, seguida por perda de 6 a $8 \mathrm{~mm}$ (29\%) (Tabela 3). O número médio de sextantes nulos por indivíduo foi de $5,4( \pm 1,4)$. Houve um aumento do número de sextantes nulos, uma redução dos sextantes com bolsa de 4 a $5 \mathrm{~mm}$ ou $\geq 6 \mathrm{~mm}$ e com PI de 4 a $5 \mathrm{~mm}$, de 6 a $8 \mathrm{~mm}$ e de 9 a $11 \mathrm{~mm}$ com o aumento da idade (Tabela 4). A distribuição percentual dos escores do CPI para cada sextante e no total de sextantes foi representada na Figura 1. O maior percentual de sextantes válidos foi observado na região ânteroinferior, onde houve menor perda dentária.

\section{Discussão}

Este estudo relata de forma sistemática a saúde bucal em idosos institucionalizados de Belo Horizonte. As características da população estudada quanto ao gênero, faixa etária, escolaridade e estado civil são comparáveis às descritas para idosos institucionalizados no Brasil 5,7,8,21,22. O predomínio de mulheres pode ser explicado pelo número absoluto de idosas ser superior ao de homens, no Brasil (Instituto Brasileiro de Geografia e Estatística. Contagem da população 2007. http://www.ibge.gov.br/home/estatisti ca/populacao/contagem2007/defaulttab.shtm, acessado em 20/Jan/2009). Isso pode ser devido a diferenças entre gêneros na mortalidade, expectativa de vida ao nascimento e utilização dos serviços de saúde 22,23. A maior institucionalização das mulheres pode ser também decorrente do fato de elas se tornarem viúvas mais cedo, apresentarem maior dificuldade para contrair o primeiro matrimônio ou se casarem após separação ou viuvez, e por exibirem menores níveis de instrução, taxa de ocupação e renda 21. Além disso, algumas instituições pesquisadas recebem somente residentes do sexo feminino, as quais, segundo relato de seus coordenadores, são mais aceitas por contribuírem com as tarefas diárias, tais como lavar roupas e cozinhar.

Metade dos idosos institucionalizados possuía 80 anos ou mais. O incremento da faixa etária acarreta maior risco de adoecer e maior grau de dependência 24 . O analfabetismo reflete o baixo nível de escolaridade predominante no idoso, que é uma realidade nos países em desenvolvimento, principalmente, para uma geração de idosos, em cuja infância o ensino não era prioridade 22 . A predominância de solteiros e viúvos talvez se dê pela perda de familiares e de 
Condição periodontal dos idosos residentes em instituições de longa permanência, segundo o índice periodontal comunitário (CPI) e o índice de perda de inserção periodontal (PIP). Belo Horizonte, Minas Gerais, Brasil, 2006.

\begin{tabular}{|c|c|c|c|c|c|}
\hline \multirow[t]{2}{*}{ Variáveis } & \multicolumn{2}{|c|}{ Indivíduos } & \multicolumn{3}{|c|}{ Sextantes } \\
\hline & $\mathrm{n}$ & $\%$ & $\mathrm{n}$ & $\%$ & $\begin{array}{c}\text { Percentual } \\
\text { em relação } \\
\text { aos } 217 \\
\text { sextantes } \\
\text { válidos }\end{array}$ \\
\hline \multicolumn{6}{|l|}{$\mathrm{CPI}$} \\
\hline Sadio & 0 & 0 & 7 & 0,3 & 3,2 \\
\hline Sangramento à sondagem & 2 & 0,6 & 14 & 0,7 & 6,5 \\
\hline Cálculo & 3 & 0,9 & 21 & 1,1 & 9,7 \\
\hline Bolsa de $4-5 \mathrm{~mm}$ & 49 & 14,8 & 140 & 7,0 & 64,5 \\
\hline Bolsa $\geq 6 \mathrm{~mm}$ & 19 & 5,7 & 35 & 1,8 & 16,1 \\
\hline Sextante nulo & 259 & 78,0 & 1.775 & 89,1 & - \\
\hline Total & 332 & 100,0 & 1.992 & 100,0 & 100,0 \\
\hline \multicolumn{6}{|l|}{ PIP } \\
\hline PI 0-3mm & 2 & 0,6 & 14 & 0,7 & 6,5 \\
\hline $\mathrm{PI} 4-5 \mathrm{~mm}$ & 14 & 4,2 & 102 & 5,1 & 47,0 \\
\hline PI 6-8mm & 31 & 9,4 & 63 & 3,2 & 29,0 \\
\hline PI 9-11 mm & 21 & 6,3 & 31 & 1,5 & 14,3 \\
\hline $\mathrm{PI} \geq 12 \mathrm{~mm}$ & 5 & 1,5 & 7 & 0,4 & 3,2 \\
\hline Sextante nulo & 259 & 78,0 & 1.775 & 89,1 & - \\
\hline Total & 332 & 100,0 & 1.992 & 100,0 & 100,0 \\
\hline
\end{tabular}

PI: perda de inserção.

companheiros. Assim, a solidão, a falta de quem lhes dê assistência ou os acolha podem ser motivos que estimulem a institucionalização.

O presente estudo revelou uma precária higiene bucal, tanto nos idosos dentados como nos usuários de prótese total superior, o que também foi observado por outros pesquisadores em idosos institucionalizados 12,25. A visão de que é natural a perda de todos os dentes com o envelhecimento pode levar os idosos a negligenciarem medidas de controle de placa. Adicionalmente, limitação física, problemas visuais e demência podem comprometer o auto cuidado, resultando em altos níveis de acúmulo de placa bacteriana 12. Muitos idosos são dependentes de um cuidador para a realização da higiene bucal, cuja provisão pode ser irregular, insatisfatória e infreqüente 26 . Um estudo qualitativo com cuidadores revelou que eles atribuem baixa prioridade ao cuidado com a boca 27 . A falta de controle adequado da placa bacteriana pode aumentar o risco de desenvolvimento de lesões de mucosa, cárie dentária e doença periodontal.

Embora o CPOD apresente pouca sensibilidade para estimar o ataque da cárie em idosos, pois não permite conhecer o verdadeiro motivo que levou à perda dentária, ele foi adotado porque continua sendo o índice mais usado nos estudos dessa população e, juntamente, com o percentual de edêntulos, tem constituído a base de comparação entre os levantamentos epidemiológicos 1 .

A experiência de cárie registrada pelo CPOD foi elevada $(30,8)$, sendo $94,2 \%$ do índice representado pelo componente perdido. Resultados semelhantes foram observados em idosos institucionalizados brasileiros, com média de CPOD variando de 29,73 a 30,91 , com componente perdido em torno de $96 \%$ do índice $5,7,8,10$. No levantamento conduzido no Brasil em 2003, os idosos de 65 a 74 anos de idade apresentaram CPOD de 27,8, com 92,95\% de dentes perdidos 2 . Em Biguaçu, Santa Catarina, Brasil, o CPOD de idosos domiciliares foi de 28,9 e 92,1\% representado pelo componente perdido 1 . Associados de grêmios e usuários de serviços de saúde apresentaram CPOD de 31,09, com componente perdido de $28,8(92,64 \%)^{3}$. De maneira geral, os valores de CPOD e a proporção de dentes perdidos dos idosos institucionalizados foram ligeira- 
Comparação entre número médio de sextantes segundo categorias do índice periodontal comunitário (CPI) e do índice de perda de inserção periodontal (PIP) por faixa etária e gênero. Belo Horizonte, Minas Gerias, Brasil, 2006.

\begin{tabular}{|c|c|c|c|c|c|c|}
\hline $\mathrm{CPI}$ & Sextante nulo & $\begin{array}{l}\mathrm{CPI}=0 \\
\text { (sadio) }\end{array}$ & $\begin{array}{c}\mathrm{CPI}=1 \\
\text { (sangramento à } \\
\text { sondagem) }\end{array}$ & $\begin{array}{l}\mathrm{CPI}=2 \\
\text { (cálculo) }\end{array}$ & $\begin{array}{c}C P I=3 \\
\text { (bolsa 4-5mm) }\end{array}$ & $\begin{array}{c}C P I=4 \\
\text { (bolsa } \geq 6 \mathrm{~mm} \text { ) }\end{array}$ \\
\hline Total & $5,4(1,4)$ & $0,02(0,2)$ & $0,04(0,3)$ & $0,06(0,3)$ & $0,42(1,0)$ & $0,10(0,4)$ \\
\hline \multicolumn{7}{|l|}{ Faixa etária (anos) } \\
\hline $60-69$ & $4,7(1,9) a$ & $0,04(0,2) a$ & $0,08(0,3) a$ & $0,08(0,3) a$ & $0,81(1,4) a$ & $0,25(0,7) a$ \\
\hline $70-79$ & $5,4(1,4) a$ & Oa & $0,03(0,2) a$ & $0,07(0,3) a$ & $0,46(1,0) a$ & $0,11(0,5) a$ \\
\hline 80 ou mais & $5,6(1,5)^{b}$ & $0,03(0,2) a$ & $0,04(0,3) a$ & $0,04(0,3) a$ & $0,27(0,8) \mathrm{b}$ & $0,05(0,3)^{b}$ \\
\hline \multicolumn{7}{|l|}{ Gênero } \\
\hline Masculino & $5,3(1,5) \mathrm{a}$ & $0,02(0,1) a$ & $0,07(0,3) a$ & $0,06(0,3) a$ & $0,38(0,8) a$ & $0,15(0,5) a$ \\
\hline Feminino & $5,4(1,4)^{a}$ & $0,02(0,2)^{a}$ & $0,03(0,3)^{a}$ & $0,06(0,3)^{a}$ & $0,43(1,0)^{a}$ & $0,09(0,4)^{a}$ \\
\hline PIP & Sextante nulo & $\begin{array}{c}P I P=0 \\
(P I 0-3 \mathrm{~mm})\end{array}$ & $\begin{array}{c}\mathrm{PIP}=1 \\
(\mathrm{PI} 4-5 \mathrm{~mm})\end{array}$ & $\begin{array}{c}P I P=2 \\
(P I 6-8 \mathrm{~mm})\end{array}$ & $\begin{array}{c}P I P=3 \\
(P I 9-11 \mathrm{~mm})\end{array}$ & $\begin{array}{c}P I P=4 \\
(P I \geq 12 \mathrm{~mm})\end{array}$ \\
\hline Total & $5,4(1,4)$ & $0,05(0,3)$ & $0,3(0,9)$ & $0,2(0,6)$ & $0,1(0,4)$ & $0,02(0,2)$ \\
\hline \multicolumn{7}{|c|}{ Faixa etária (anos) } \\
\hline $60-69$ & $4,7(1,9)^{a}$ & $0,04(0,2)^{a}$ & $0,8(1,5)^{a}$ & $0,4(0,7)^{a}$ & $0,06(0,2) a b$ & $0,04(0,2)^{a}$ \\
\hline $70-79$ & $5,4(1,4) a$ & $0,03(0,2) a$ & $0,3(0,8) \mathrm{ab}$ & $0,2(0,7) \mathrm{ab}$ & $0,2(0,5) b$ & $0,01(0,1) a$ \\
\hline 80 ou mais & $5,6(1,5) b$ & $0,07(0,4) a$ & $0,2(0,7)^{b}$ & $0,1(0,4) b$ & $0,05(0,4) \mathrm{ac}$ & $0,01(0,2) a$ \\
\hline \multicolumn{7}{|l|}{ Gênero } \\
\hline Masculino & $5,3(1,5) a$ & $0,05(0,3) a$ & $0,3(0,9) a$ & $0,2(0,5) a$ & $0,08(0,4) a$ & $0,01(0,1) a$ \\
\hline Feminino & $5,4(1,4) a$ & $0,01(0,1) a$ & $0,3(1,0) a$ & $0,2(0,6) a$ & $0,1(0,5) a$ & $0,04(0,3) a$ \\
\hline
\end{tabular}

PI: perda de inserção.

Nota: a comparação foi realizada empregando teste Kruskall-Wallis e teste Mann Whitney com correção de Bonferrone para a comparação em pares ( $p<0,05$ para gênero, $\mathrm{p}<0,02$ para faixa etária). As letras diferentes comparadas verticalmente significam diferença estatística significativa.

Figura 1

Distribuição percentual das categorias do índice periodontal comunitário (CPI) por sextantes estudados nos idosos institucionalizados. Belo Horizonte, Minas Gerais, Brasil, 2006

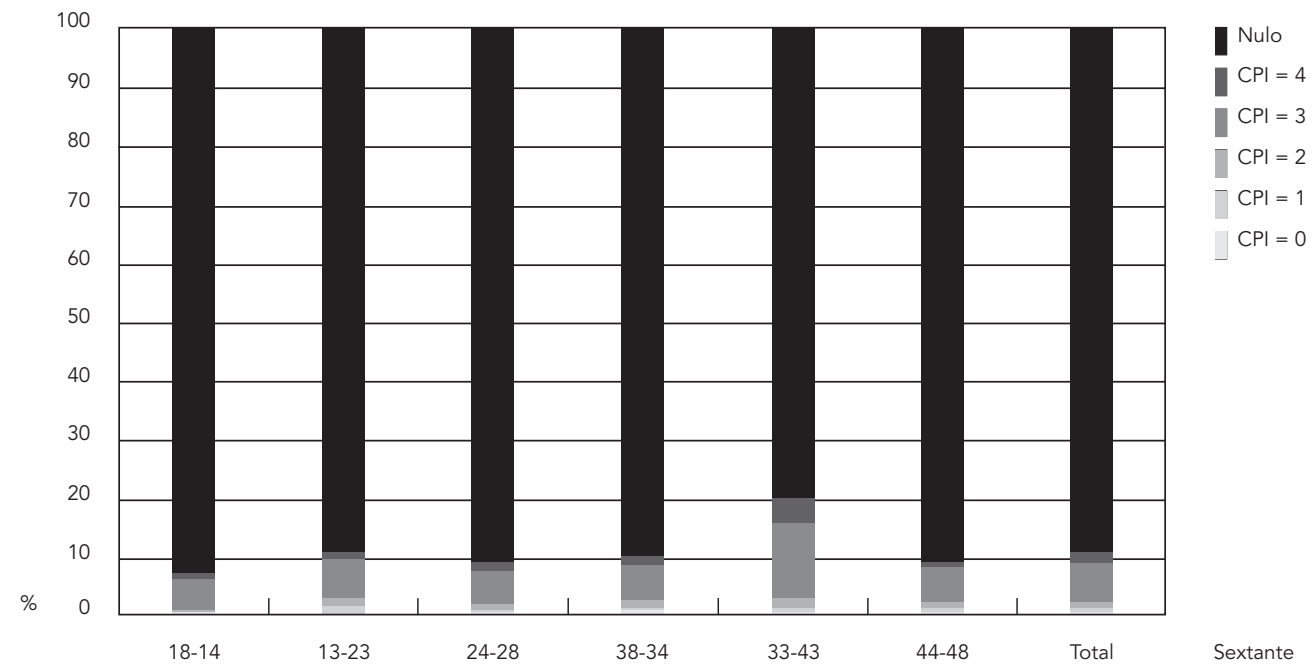


mente maiores que dos não-institucionalizados, mas, no conjunto, representam o elevado grau da perda dentária entre idosos brasileiros e o distanciamento dessa situação em relação às metas da OMS, para o ano 2000 , de $50 \%$ da população idosa com vinte dentes ou mais presentes na boca. Reforçando esse achado, observou-se também alta taxa de edentulismo $(74,9 \%)$ e reduzido número médio de dentes remanescentes por indivíduo $(3,0)$. A prevalência de edentulismo observada no presente estudo foi mais elevada do que entre idosos institucionalizados em Fortaleza 7 (58,1\%), zona leste de São Paulo 8 (68,3\%), Goiás 10 (69,2\%) e Araraquara 5 (72\%) e mais baixa do que a observada em São Paulo $(83,6 \%) 28$. De maneira semelhante, outros estudos mostraram idosos institucionalizados com 2,5 e 5,0 dentes remanescentes, em mé dia 7,8. A perda dentária nos idosos pode refletir o efeito da prática odontológica mutiladora ao longo da vida desses indivíduos, bem como o descaso com que este grupo foi e ainda é considerado 3 , evidenciado também pelo grande número de idosos edêntulos sem próteses 10,29.

O aumento do índice CPOD com o aumento da idade, atribuído principalmente ao aumento do componente perdido, era esperado e foi previamente observado ${ }^{30}$. Entretanto, não houve diferença quanto ao gênero, diferentemente do que foi observado por outros pesquisadores em idosos institucionalizados 8,29. A experiência de cárie em idosos institucionalizados de diferentes regiões do mundo pode ser menor 13,25,30 ou similar 31 à dos estudos brasileiros, refletindo a influência de condições sócio-econômicas, padrões culturais, dietéticos, dentre outros fatores, na condição de saúde bucal de uma população.

Nesse estudo, 58,4\% dos dentes presentes apresentavam superfície radicular exposta devido à recessão gengival, representando uma área de estagnação de placa e, conseqüentemente, com maior risco de desenvolvimento de cárie. Entretanto, a grande maioria de raízes expostas encontrava-se hígida (76\%), de forma similar aos estudos realizados em instituições de idosos em Piracicaba $(84,1 \%)^{6}$ e Fortaleza $(84 \%){ }^{7}$. Aproximadamente metade dos idosos apresentaram pelo menos uma superfície radicular com lesão de cárie, prevalência maior que a observada em uma população de idosos que freqüentavam grêmios ou serviços municipais de saúde em cidades da região sudeste de São Paulo $(31,8 \%) 9$. A prevalência de cárie radicular em idosos institucionalizados no Brasil pode ser considerada baixa se comparada aos resultados de estudos realizados no Canadá (80\%), na França (88\%) e na Finlândia (52\%) 32,33,34. Essa diferença não reflete, necessariamente, uma pior saúde bu- cal nessas populações, mas provavelmente, um maior número de idosos dentados e de dentes remanescentes, comparados aos idosos brasileiros. Espera-se, no futuro, um aumento do contingente de pessoas com cárie de raiz, uma vez que uma parcela maior da população deverá manter seus dentes naturais por mais tempo, implicando necessidade de capacitação dos profissionais para o diagnóstico e adoção de medidas de controle 9 .

No presente estudo, a perda dentária foi também evidenciada pelo baixo percentual de indivíduos com sextantes válidos para a avaliação periodontal, e, esses indivíduos apresentaram maior prevalência de bolsas periodontais de 4 a $5 \mathrm{~mm}$, o que também foi observado entre idosos institucionalizados de Araraquara 5. Entretanto, outros estudos com idosos institucionalizados mostraram presença de cálculo como a condição periodontal mais freqüente entre indivíduos ou sextantes válidos 6,7,8,10. Essa diferença pode ser explicada pelo fato de que, no presente estudo, a raspagem supragengival foi realizada previamente à sondagem periodontal quando da presença de cálculo inviabilizando tal procedimento, conduta adotada para evitar a subestimativa da condição periodontal.

Quanto ao PIP, desconsiderando sextantes nulos, a maior porcentagem de idosos apresentou perda de inserção entre 6 e $8 \mathrm{~mm}$. Na avaliação dos sextantes válidos, predominou perda de 4 a $5 \mathrm{~mm}$, seguida de 6 a $8 \mathrm{~mm}$. Resultado semelhante foi observado em idosos institucionalizados de São Paulo ${ }^{8}$. Por outro lado, entre idosos de Goiânia, Estado de Goiás, houve um predomínio de sextantes sadios, com perda de inserção de até $3 \mathrm{~mm}{ }^{10}$, que pode ter sido mascarada pela presença de cálculo, registrada como condição mais prevalente no CPI. No presente estudo, os poucos dentes remanescentes, com perda da inserção periodontal, associada à inadequada higiene bucal, apresentam maior risco para a extração dentária, caso medidas de controle não sejam implantadas.

A condição periodontal observada no presente estudo e em outros estudos com idosos institucionalizados brasileiros é pior do que a demonstrada no levantamento nacional realizado em 2003, cuja análise do CPI e PIP mostrou predomínio de cálculo e maior freqüência de sextantes com perda de inserção de 0 a 3mm 2,35. Outro estudo com idosos usuários de serviços de saúde e associados de grêmios, em São Paulo, mostrou que $70,4 \%$ dos idosos apresentaram $\mathrm{CPI}=0$ 3. Maior predomínio de bolsas periodontais entre idosos institucionalizados, em relação aos não-institucionalizados foi previamente observado 5 , entretanto os autores não discuti- 
ram os motivos dessa diferença. Provavelmente, fatores determinantes, resultantes ou estimuladores da institucionalização, bem como relacionados ao estilo de vida na instituição podem ser relacionados com essas desigualdades. Essas hipóteses deverão ser investigadas em futuros estudos.

A população de idosos institucionalizados estudada é formada, na sua maioria, por indivíduos com renda e escolaridade baixas, metade com mais de 80 anos de idade. Essas características são fatores determinantes da institucionalização, além da presença de doenças crônicodegenerativas e suas seqüelas, a hospitalização recente, dependência, morar sozinho e suporte social precário 21. "Ser/estar na condição de idoso institucionalizado revela a contradição da inclusão-exclusão dos idosos na sociedade" 36 (p. 144). Pelo fato de as instituições para idosos serem excluídas de políticas públicas, principalmente de saúde bucal, o idoso institucionalizado encontra-se ainda mais excluído do acesso à atenção e assistência odontológicas públicas 36 . As demandas presentes nessas instituições deveriam ser reconhecidas e atendidas pelo Estado brasileiro, garantindo o acesso pleno do idoso ao Sistema Único de Saúde (SUS). O Programa Saúde da Família (PSF) atuaria como elo entre o idoso e os serviços de saúde, possibilitando também a atenção domiciliar para os idosos dependentes 37 . Facilitar o acesso aos serviços odontológicos, seja nos centros de saúde ou no atendimento domiciliar e unidades móveis, juntamente com a conscientização da equipe de cuidadores sobre a importância da manutenção da saúde bucal contribuiria para uma melhora no quadro geral do idoso e preservação de sua autonomia. A odontologia pode influenciar o suporte social, na medida em que mantém a saúde bucal do idoso, possibilitando a este uma aparência agradável, melhor auto-estima, maior capacidade de fonação, contribuiria para a integração do idoso no meio social 24. A adoção da estratégia do fator de risco comum para promoção da saúde, atuando no controle de fatores como dieta, fumo, uso de álcool, estresse, trauma, sedentarismo, na prevenção de diversas doenças crônicas ${ }^{38}$, deslocaria o foco para além dos limites da cavidade bucal, incluindo características da vida dos idosos e os fatores determinantes do seu processo de viver e ser saudável 39.

Atualmente, as políticas públicas de saúde, como a Política Nacional de Saúde Bucal do Ministério da Saúde, buscam ampliação e qualificação da atenção básica, mediante a inclusão de procedimentos como a reabilitação protética, cuja necessidade é alta na população. Assim, a atenção deveria incluir idosos institucionaliza- dos, principalmente aqueles que não dispõem de cuidados familiares. Com essas medidas, surge uma nova perspectiva de melhora futura da saúde bucal da população idosa.

Ressalta-se que a abordagem do idoso deve diferir da população geral, considerando-se a diversidade biopsicossocial e a complexidade clínica freqüentemente associada ao envelhecimento. Torna-se fundamental a atuação do cirurgião-dentista, juntamente a uma equipe interdisciplinar, capacitada a lidar com as contradições existentes na definição de saúde, doença e necessidade de tratamento.

Os determinantes da incorporação de práticas de higiene bucal nas instituições devem ser avaliados para direcionar ações para promovêla, uma vez que favorecerão obtenção e a manutenção de boas condições de saúde. Métodos de acompanhamento e avaliação dos resultados devem ser incorporados para medir o impacto das ações de promoção e reabilitação da saúde e seus efeitos na qualidade de vida dos idosos.

O cuidado à saúde bucal é uma construção que se dá ao longo da vida das pessoas e por isso, a formulação de políticas públicas não pode ser concretizada por meio da implementação de ações pontuais, de curto prazo, mas de modo processual, dinâmico, na perspectiva do envelhecimento saudável, respeitando integralmente as demandas de todos os ciclos da vida 39 .

\section{Conclusões}

Com base nos resultados apresentados, pode-se concluir que:

- Nas instituições de Belo Horizonte, a população de idosos é predominantemente feminina, formada por indivíduos com mais de 80 anos, viúvos ou solteiros e de baixa escolaridade;

- A higiene bucal dos idosos institucionalizados, em geral, é precária. Um alto valor de CPOD revela a severidade da doença cárie e suas conseqüências entre os idosos, que possuem um número reduzido de dentes remanescentes. Entre eles, a experiência de cárie radicular é baixa;

- Um elevado grau de perda dentária foi constatado pelo percentual de componentes perdidos no CPOD, grande número de sextantes excluídos no CPI e alta taxa de edentulismo;

- A doença periodontal acomete os poucos dentes remanescentes, que apresentam bolsas periodontais rasas ou profundas, gengivite e cálculo. 


\section{Resumo}

Este estudo transversal descreveu a saúde bucal de idosos residentes em instituições de longa permanência de Belo Horizonte, Minas Gerais, Brasil. Uma amostra de 335 idosos acima de 60 anos de idade foi aleatoriamente selecionada. Os dados foram coletados dos registros das instituições, por entrevista e exame clínico da cavidade bucal. Avaliaram-se a higiene bucal, a cárie dentária coronária e radicular e a doença periodontal. Foi observada placa bacteriana em $76 \%$ das superficies dentárias e 57\% dos idosos usuários de prótese total superior apresentaram placa em pelo menos uma das superfícies. O CPOD foi de 30,8, com predomínio do componente perdido (94,2\%) e 57,1\% dos idosos apresentaram experiência de cárie radicular. A maioria dos idosos $(78,2 \%)$ apresentou como pior condição periodontal sextante nulo e $64,5 \%$ dos sextantes válidos apresentaram bolsa periodontal de $4 \mathrm{~mm}$ a $5 \mathrm{~mm}$ e 47\% perda inserção de $4 \mathrm{~mm}$ a $5 \mathrm{~mm}$ (47\%). A saúde bucal dos idosos é precária, representada por higiene bucal deficiente, alta experiência de cárie, acentuada perda dentária e presença de bolsa periodontal.

Instituição de Longa Permanência para Idosos; Saúde Bucal; Saúde do Idoso

\section{Referências}

1. Colussi CF, Freitas SFT, Calvo MCM. Perfil epidemiológico da cárie e do uso e necessidade de prótese na população idosa de Biguaçu, Santa Catarina. Rev Bras Epidemiol 2004; 7:88-97.

2. Ministério da Saúde. SB Brasil 2003: condições de saúde bucal da população brasileira 2002-2003. Resultados principais. Brasília: Ministério da Saúde; 2004.

3. Silva DD, Sousa MLR, Wada RS. Saúde bucal em adultos e idosos na cidade de Rio Claro, São Paulo, Brasil. Cad Saúde Pública 2004; 20:626-31.

4. Pereira AC, Castellanos RA, Silva SRC, Watanabe MGC, Queluz DP, Meneghim MC. Oral health and periodontal status in Brazilian elderly. Braz Dent J 1996; 7:97-102.

5. Silva SRC, Valsecki Jr. A. Assessment of oral health in an elderly Brazilian population. Rev Panam Salud Pública 2000; 8:268-71.

6. Meneghim MC, Pereira AC, Silva FRB. Prevalência de cárie radicular e condição periodontal em uma população idosa institucionalizada de Piracicaba SP. Pesqui Odontol Bras 2002; 16:50-6.

\section{Colaboradores}

R. C. Ferreira realizou a coleta, análise e interpretação dos dados, participou na revisão da literatura e foi a redatora principal do artigo. C. S. Magalhães orientou o trabalho e contribuiu na edição e revisão final do artigo. E. S. Rocha participou da coleta de dados e contribuiu para a redação do artigo. C. W. Schwambach participou da coleta de dados e da redação do artigo. A. N. Moreira idealizou e orientou o trabalho e contribuiu na edição e revisão final do artigo.

\section{Agradecimentos}

Este estudo foi financiado pelo Conselho Nacional de Desenvolvimento Científico e Tecnológico (CNPq) e Ministério da Saúde (projeto no ${ }^{\circ}$ 403244/2004-8 - Edital Saúde Bucal). Os autores agradecem a Promotoria de Defesa das Pessoas Portadoras de Necessidades Especiais e do Idoso, bem como os idosos, seus cuidadores e os coordenadores das instituições de longa permanência para idosos de Belo Horizonte.
7. Gaião LR, Almeida MEL, Heukelbach J. Perfil epidemiológico da cárie dentária, doença periodontal, uso e necessidade de prótese em idosos residentes em uma instituição na cidade de Fortaleza, Ceará. Rev Bras Epidemiol 2005; 8:316-23.

8. Carneiro RMV, Silva DD, Sousa MLR, Wada RS Saúde bucal de idosos institucionalizados, zona leste de São Paulo, Brasil, 1999. Cad Saúde Pública 2005; 21:1709-16.

9. Rihs LB, Sousa MLR, Wada RS. Prevalência de cárie radicular em adultos e idosos na região sudeste do Estado de São Paulo, Brasil. Cad Saúde Pública 2005; 21:311-6.

10. Reis SCGB, Higino MASP, Melo HMD, Freire MCM Oral health status of institutionalized elderly in Goiânia-GO, Brazil, 2003. Rev Bras Epidemiol 2005; 8:67-73.

11. Slade GD, Locker D, Leake JL, Price SA, Chao I. Differences in oral health status between institutionalized and non-institutionalized older adults. Community Dent Oral Epidemiol 1990; 18:272-6. 
12. De Visschere LM, Grooten L, Theuniers G, Vanobbergen JN. Oral hygiene of elderly people in longterm care institutions - a cross sectional study. Gerodontology 2006; 23:195-204.

13. Montal S, Tramini P, Triay JA, Valcarcel J. Oral hygiene and the need for treatment of the dependent institutionalized elderly. Gerodontology 2006; 23:67-72.

14. Shay K. Infectious complications of dental and periodontal diseases in the elderly population. Clin Infect Dis 2002; 34:1215-23.

15. Brucki SMD, Nitrini R, Caramelli P, Bertolucci PHF, Okamoto IH. Sugestões para o uso do mini-exame do estado mental no Brasil. Arq Neuropsiquiatr 2003; 61:777-81.

16. Nitrini R, Caramelli P, Bottino CMC, Damasceno BP, Brucki SMD, Anghinah R. Diagnóstico de doença de Alzheimer no Brasil: avaliação cognitiva e funcional. Arq Neuropsiquiatr 2005; 63:720-7.

17. Silness J, Löe H. Periodontal disease in pregnancy. II Correlation between oral hygiene and periodontal condition. Acta Odontol Scand 1964; 22:121-35.

18. Ainamo J, Bay I. Problems and proposals for recording gingivitis and plaque. Int Dent J 1975; 25:229-35.

19. Ambjornsen E, Valderhaug J, Norheim PW, Floystrand F. Assessment of an additive index for plaque accumulation on complete maxillary dentures. Acta Odontol Scand 1982; 40:203-8.

20. World Health Organization. Oral health surveys: basic methods. $4^{\text {th }}$ Ed. Geneva: World Health Organization; 1997.

21. Chaimowicz F, Greco DB. Dinâmica da institucionalização de idosos em Belo Horizonte, Brasil. Rev Saúde Pública 1999; 33:454-60.

22. Davim RMB, Torres GV, Dantas SMM, Lima VM. Estudo com idosos de instituições asilares no município de Natal/RN: características socioeconômicas e de saúde. Rev Latinoam Enferm 2004; 12: 518-24.

23. Ramos LR, Veras RP, Kalache A. Envelhecimento populacional: uma realidade brasileira. Rev Saúde Pública 1987; 21:211-24.

24. Araújo SSC, Freire DBL, Padilha DMP, Baldisserotto J. Suporte social, promoção de saúde e saúde bucal na população idosa no Brasil. Interface Comun Saúde Educ 2006; 10:203-16.

25. Chalmers JM, Carter KD, Fuss JM, Spencer AJ, Hodge CP. Caries experience in existing and new nursing home residents in Adelaide, Australia. Gerodontology 2002; 19:30-40.
26. Coleman P. Opportunities for nursing-dental collaboration: addressing oral health needs among the elderly. Nurs Outlook 2005; 53:33-9.

27. Wardh I, Hallberg LR, Berggren U, Andersson L, Sörensen S. Oral health care: a low priority in nursing. In-depth interviews with nursing staff. Scand J Caring Sci 2000; 14:137-42.

28. Rosa AGF, Fernandez RAC, Pinto VG, Ramos LR. Condições de saúde bucal em pessoas de 60 anos ou mais no município de São Paulo (Brasil). Rev Saúde Pública 1992; 26:155-60.

29. Ferreira RC, Magalhães CS, Moreira AN. Tooth loss, denture wearing and associated factors among an elderly institutionalized Brazilian population. Gerodontology 2008; 25:168-78.

30. Lo ECM, Luo Y, Dyson JE. Oral health status of institutionalized elderly in Hong Kong. Community Dent Health 2004; 21:224-6.

31. Adam H, Preston AJ. The oral health of individuals with dementia in nursing homes. Gerodontology 2006; 23:99-105.

32. Banting DW, Ellen RP, Fillery ED. Prevalence of root surface caries among institutionalized older persons. Community Dent Oral Epidemiol 1980; 8:84-8.

33. Guivant-Nabet C, Tavernier M, Trevoux C, Berdal A. Active and inactive caries lesions in a selected elderly institutionalized French population. Int Dent J 1998; 48:111-22.

34. Narhi TO, Vehkalahti MM, Siukosaari P, Ainamo A. Salivary findings, daily medication and rooth caries in the old elderly. Caries Res 1998; 32:5-9.

35. Martins AMEBL, Melo FS, Fernandes FM, Boa Sorte JA, Coimbra LGA, Batista RC. Levantamentos epidemiológicos brasileiros das condições de saúde bucal. Unimontes Científica 2005; 7:55-66.

36. Mello ALSF, Erdmann AL. Revelando contradições e incorporando melhores práticas no cuidado à saúde bucal de idosos. Physis (Rio J.) 2007; 17: 139-56.

37. Silvestre JA, Costa-Neto MM. Abordagem do idoso em programas de saúde da família. Cad Saúde Pública 2003; 19:839-47.

38. Sheiham A, Watt RG. The common risk factor approach: a national basis for promoting oral health. Community Dent Oral Epidemiol 2000; 28: 399-406.

39. Mello ALSF, Erdmann AL, Caetano JC. Saúde bucal do idoso: por uma política inclusiva. Texto \& Contexto Enferm 2008; 17:696-704.

\footnotetext{
Recebido em 28/Jan/2009

Versão final reapresentada em 25/Jun/2009

Aprovado em 03/Set/2009
} 